\title{
The Research of Enterprise Strategic Planning Based on Balanced Score Card
}

\author{
Li Qin
}

Tourism and Culture College of Yunnan University, Yunnan, China, 674100

Keywords: balanced score card; strategic planning; operating procedures; implementing measures

\begin{abstract}
Balanced score card plays a very important role in enterprise strategic management, and carrying out strategic planning of enterprises based on balanced score card is beneficial to the realization of sustainable development goals of enterprises. In this context, this paper first clarifies the necessity of the integration of BSC and strategic planning work, then analyzes the composition and operation flow of BSC, gives the strategic planning measures based on BSC, and finally, gives a summary.
\end{abstract}

\section{Introduction}

With the globalization, the international business environment has changed dramatically. In the course of intense competition, the enterprises must constantly innovate and grow in order to survive. Therefore, the enterprise vision and business strategy must be drawn up to gain a competitive advantage so as to lead members of the organization to reach the goals set by the enterprises. How to structure competitive advantage and integrate enterprise resources in business strategy is a topic that the current managers must face seriously.

\section{The Necessity of Integrating Balanced Score Card with Strategic Planning}

In thinking about how to maintain competitive advantage, how to enable enterprises to maintain their unique and superior competitive position relative to their competitors in the industry and to show their competitive advantages as higher market share or better profitability so as to enhance shareholder value, Is the ultimate goal of business operations. The competitive advantage derives from the value created for the customer, the firm can offer a product or service that is lower in price and of the same interest than the competitor, or a specially tailored product or service at an equal or higher price to create higher value for customers.

Currently, the external environment of enterprises faces the price competition from international competitors while the internal ones face the tough operating environment of domestic land cost, capital cost, rising raw materials and labor force. How to maintain innovation and maintain the competitive edge and establish the competitive threshold will be Important topic. For this reason, enterprises need to formulate different development and competition strategies in operation and management in order to cope with changes in industries and strong competitors' challenges. However, are the competition strategies and strategic objectives fully supported by the members of the organization and their implementation can be implemented Depending on whether the enterprise can construct a systematic and measurable performance management system.

However, in today's global environment where competition in the environment is intense, the traditional performance evaluation emphasizes financial indicators as a comprehensive and balanced performance evaluation strategy. Balanced scorecard is a kind of strategy that brings the organizational strategy Implementation of the management system. The Kaplan and Norton research teams started their research on the indicators of the organization's business performance in 1990 in the hope of objectively presenting the results of all the efforts of the organization's members. The Balanced Scorecard emphasizes the importance of the business in four areas: financial, customer, Internal processes, learning and growth) performance measures should be derived from the strategy, and should be able to link with the enterprise reward system. In other words, the Balanced Scorecard is not only a performance measurement system, but also a 
management tool that links with strategic planning and reward system. It helps companies to guide the implementation of the strategy and achieve the strategic goal through the formulation of competitive strategy and strategic formulation, through measurable management indicators. Because the Balanced Scorecard measures both financial and nonfinancial dimensions, it embodies the strategy as an enforceable plan that not only allows the organization's members to understand the business vision more specifically and in depth, but also makes it easier for the business community to grasp The results of strategic implementation and the face of change can be changed in real time strategic response.

\section{Balanced Score Card Composition and Operation Procedure}

\subsection{Balanced score card composition}

The balanced scorecard refers to the balance as the main criterion in the enterprise short-term goals, financial and non-financial indicators, advanced and backward standards, internal and external performance in four areas to achieve a balance. Under the current economic background, enterprises must constantly strengthen their investment in a number of businesses such as customers, employees, production, research and development so as to meet the demand of future value creation. However, the traditional evaluation of such investment by means of financial indexes can not guarantee the maximum value of these investments The Balanced Scorecard provides a more advanced indicator system and measurement method. Balanced Scorecard indicators and metrics are derived from the corporate strategic vision, including the four aspects of performance evaluation content, that is, financial, customer, operational processes, learning and growth. This means that the performance score of Balanced Scorecard goes far beyond traditional financial indicators while emphasizing the current ability of the business to create value for the future and to guide businesses to more effectively allocate resources to businesses that contribute to sustainable growth The goal, for customers, employees and businesses to create the greatest value.

\subsection{Balanced score card design and implementation procedure}

When designing and planning a company's balanced scorecard, Kaplan and Norton, combined with their mentoring experience, summed up a typical system development plan that divides the creation of a balanced scorecard into four major steps:

First, establish a measurement structure. The one hand, select the appropriate organizational unit. Most companies are highly diversified and it is difficult to structure head office-level scorecards from the beginning, so the first scorecard process is best chosen in a strategic business unit. On the other hand, identify the relationship between SBU and head office. After defining and selecting the SBUs, you need to understand the financial goals of the SBU and guide all the head office characteristics (environment, safety, employee policies, community relations, quality, price competitiveness, etc.) and the links with other SBUs.

Second, establish a consensus on the strategic objectives. First, conduct the first round of interviews: gather and share background data, including the mission, vision, value, strategy, competitive position and functional competencies of the organization. Second, drafting a tentative goal and measure, as the basis for the next stage of the discussion. Finally, the first phase of the workshop: Get senior management teams fully informed of the organization's mission, values, vision and strategy and engage in collective debate until a consensus is reached.

Third, select strategic measures. First, a sub-team meeting. Acknowledging that the strategic objectives are consistent with the objectives of the first phase of the workshop, establishing a measure of each objective, identifying the sources of measurement and the actions required to obtain the information, establishing the primary linkage between the same intra-measure and the other aspects The relationship between the card surface. In turn, a second phase implementation workshop will be held. Let senior executives and mid-level managers debate the organization's vision and strategic statement together with a tentative scorecard goal measure. According to Kaplan and Norton, the design steps for a balanced scorecard are summarized. The top level is a 
vision statement. What is the future vision of the enterprise? The second layer is based on vision developed by the Balanced Scorecard four facets, the third layer to assess the key success factors for enterprises, the bottom of the key indicators for the assessment.

Fourth, develop an implementation plan. First, develop an implementation plan. Including how to link metrics to databases and information systems, how to spread a balanced scorecard across the organization, and how to encourage and assist decentralized units in developing lower-level metrics. Second, the implementation of the third phase of the implementation of the seminar. The final consensus was reached on the vision, goals and measurements developed in the previous two seminars and the initial action plan needed to reach the target.

Fifth, attach great importance to the difficulties encountered in implementing a balanced scorecard. Kaplan and Norton, in their guidance on the introduction of a balanced scorecard, consider that it is not everyone's experience of success that various manufacturing and service managers create a balanced scorecard in their institution. After analyzing their experience, it was found that the factors that may cause the BSC to fail include the structural defects and selection errors of the BSC and the organizational defects in the development of the BSC and the user.

\section{Strategic Planning Measures Based on Balanced Score Card}

Since Kaplan and Norton advocated the Balanced Scorecard system in 1992, the system has become an important technology in the field of strategic management. As the two scholars put it, many organizations suffer setbacks because of the lack of strategy or The quality of the strategy is not good enough, but the lack of implementation of the strategy of the organization's execution, thus affecting the business success. Balanced Scorecard provides a systematic framework and method of thinking that focuses on the organization's overall resources and actions in a strategic manner to enable the specific actions of the strategy to take full advantage of the overall strength of the enterprise and continue to achieve the goal of success. Based on the Balanced Scorecard to carry out strategic planning, should do the following key tasks.

\subsection{Establish a balanced score card management system}

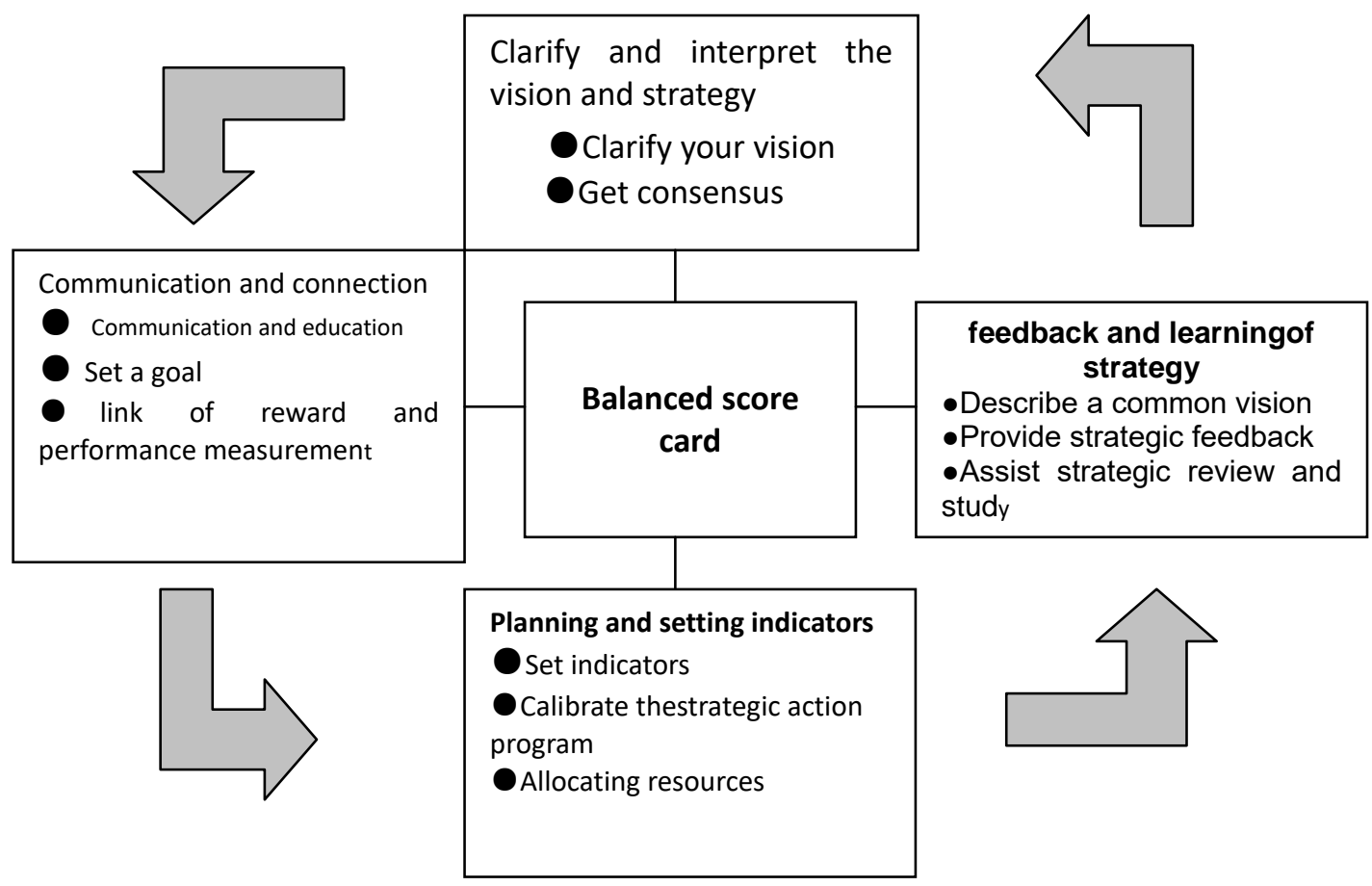

Figure 1 Strategic Planning Action Framework Based on Balanced Score card

Balanced scorecards focus on the financial and non-financial measures that must be combined with the information system and should affect all employees up and down the organization. The goal and measurement of a balanced scorecard do not simply randomize the measurement of 
financial and non-financial performance, which is driven by a business process and strategy driven by a top-down process. Balanced scorecards reflect the strategic vision of an organization that transforms strategic vision into concrete goals that can be objectively measured. Therefore, the Balanced Scorecard depicts the external and internal balance of two different measures, the external aspects of the specific needs of customers and shareholders, and internal aspects of the enterprise's own business processes and continuous innovation ability. In addition, the Balanced Scorecard also has a time-series nature, focusing not only on the results of previous efforts of the business, but also on how to achieve better performance in the future. This means that a balanced scorecard has strategic attributes and is a strategic planning framework that guides the business in an orderly fashion (Figure 1).

Specifically, the following work must be concerned about:

First, to clarify and interpret the vision and strategy. To implement the process of converting the vision of Balanced Scorecard, the organization's top management must establish the strategy of the organization and transform the strategy into a strategic one. At the same time that the financial goals are formulated, what are the core of the strategy that the management must consider? Is the growth of revenue and market share, or increase profitability. Regardless of the core of the strategy, the business class must clearly state what their expectations and expectations are.

\subsection{Ensure that balanced score card is effectively linked to the strategic planning}

Kaplan and Norton argue that the following three principles need to be followed in order to establish a Balanced Scorecard that can be used as a strategy measure: The first principle is the principle of causation, that is, the BSC's choice of a specific measure must be strictly followed The causal relationship between business strategies makes it a part of this causal relationship to ensure effective delivery of strategic direction to employees. The second principle is the absolute and relative validity of the results, which are the criteria for a balanced scorecard at the same time, attention should be paid to the business performance of a single organization. The third principle should be to assess the industrial status of the achievements made. The third principle is financial linkage, that is, a balanced scorecard must retain the strong appeals for results, especially the return on capital employed or the additional Economic value of the financial results.

\subsection{Strengthen the strategic management of balanced score card}

According to the long-term scholars' theoretical and practical experience in studying BSC, the BSC can play a role in the BSC after the company's strategy is formed. The BSC should include "Strategic Issues", "Strategic Objectives," "Strategy "Strategic Measurement", "Target Value of Strategic Measurement Indicators", "Strategic Action Plan", "Strategic Budget" and "Strategic Rewards". The "Strategic Systems", "Measurement Systems", "Executive System "," communication system "four systems, balanced scorecard four facets, seven elements and four systems should be interconnected.

\section{Conclusion}

This study explores the formulation of enterprise strategic planning from the point of view of balanced scorecard. It considers that enterprises can achieve the mission and vision of the organization through strategic planning, and then proceed to develop a balanced scorecard at the grassroots level and adopt specific action plans and measurable The performance indicators make the BSC a key factor in the success of the core strategy and bring together the centripetal forces and consensuses of business managers, grassroots department heads and employees.

The combination of a balanced scorecard and strategic planning can better achieve the company's vision. During the specific operation, the board of directors, chairman, general manager and management should fully discuss and confirm the company's business mission and vision, and announce the company's vision and mission with the grassroots supervisors. With product leadership, low total cost and total customer solutions For the core strategy, based on the development of finance, customers, internal processes, learning and growth of the four aspects of 
the balanced scorecard.

\section{References}

[1] Yongmei Wang. The Application Analysis of Balanced Score card in Enterprise Performance Management [J]. Friends of accounting,2015(02):67-71

[2] Jie Wu, Wei Zhou. Design of Performance Evaluation System of Financial Sharing Service Center--- Based on Balanced Scorecard and Analytic Hierarchy Process [J]. Accounting Monthly, 2015(13):10-15.

[3] Ling Chen. Application Research of Sustainable Balanced Score card [J]. Business Economics Research, 2016(23):113-114.

[4] Junnan Hu, Jing Zhang, Hao Deng. Construction of Performance Evaluation Index System of Railway Transport Enterprises Based on Balanced Scorecard[J]. Railway Transport and Economy, 2017,39(02):70-74+84.

[5] Jianling Liu. Research on the Establishment of Performance Evaluation System of Publishing Enterprises Based on Balanced Scorecard[J]. Technology and publishing, 2017(07):39-43. 